\title{
aniki
}

Revista Portuguesa da Imagem em Movimento Portuguese Journal of the Moving Image

\section{O colorido de Breaking Bad: excessos narrativos e seus efeitos nas interpretações dos fãs

\author{
Wanderley Anchieta ${ }^{1}$
} \\ Jonas Pilz ${ }^{2}$}

\section{Introdução}

A narratologia de cunho estruturalista ${ }^{3}$ costuma avalizar a disposição das narrativas em uma separação funcional entre história e discurso ${ }^{4}$, na qual a primeira consiste numa espécie de abstração lógica executada pelo leitor/espectador conforme o mesmo adentra pela superfície material da segunda, cuja manifestação se torna impreterível organização daquilo que se quer transmitir, pelo autor. Em outras palavras a história é o composto de ideias que se quer levar a outrem, e o discurso é a maneira como essas ideias são efetivamente levadas a esse outrem. Se esse conceito fosse trabalhado de forma tão elástica, praticamente qualquer manifestação textual poderia ser considerada narrativa: uma receita de bolo, afinal, aduz ideias e as organiza numa sequência. Assim, os requerimentos mínimos para que a história seja narrativa se dão quando "algo perturba a situação dada"; então, uma situação nova e possivelmente final deve ser estabelecida, uma vez que toda a peripécia provocada pela perturbação inicial tenha se esgotado" (Gaudreault 2009, 24; tradução nossa).

Dessa definição mais rigorosa proposta por André Gaudreault se elimina posts curtos na Internet, em geral, e receitas de bolo. No entanto, o foco teórico - e o da vivência experiencial ${ }^{6}$ das narrativas, conforme argumentação central deste texto - segue pesadamente

1 Instituto de Arte e Comunicação Social/Programa de Pós-Graduação em Comunicação, Universidade Federal Fluminense, CEP 24210-510, Niterói, Rio de Janeiro, Brasil.

2 Instituto de Arte e Comunicação Social/Programa de Pós-Graduação em Comunicação, Universidade Federal Fluminense, CEP 24210-510, Niterói, Rio de Janeiro, Brasil.

${ }^{3}$ Conforme linhagem de autores que a trabalharam, dentre os quais se pode destacar: Vladimir Propp, Roland Barthes, Claude Bremond, Tzvetan Todorov, Umberto Eco, Gerard Genette, Seymour Chatman, Edward Branigan, David Bordwell, etc.

4 "A fábula (ou história) é o esquema fundamental da narração, a lógica das ações e a sintaxe dos personagens, o curso de eventos ordenado temporalmente. [...] O enredo (ou discurso), pelo contrário, é a história como de fato é contada, tal como aparece na superfície, com as suas deslocações temporais, seus saltos para frente e para trás [...], descrições, digressões" (Eco 1993, 145-146; tradução e grifo nosso).

5 Propp a nomeia de "situação inicial" em sua obra seminal, Morfologia do Conto Maravilhoso.

6 Expressas através de manifestações na Internet, por fãs, sobre a interioridade/"psicologia” dos personagens através de sua caracterização; ainda em termos de tentativas de inferir o final das histórias, que ocorrerão no mesmo capítulo ou nos próximos. 
assentado sobre a história; ou seja, na evolução dos fatos e não sobre o modo como os mesmos são apresentados. É uma escolha que se manifesta no fato de que boa parte dos produtos audiovisuais não investe seu tempo de produção e/ou verba em pequenas variações discursivas de potentes efeitos estéticos e emocionais. Ademais, é mais provável que a atenção seja direcionada, de forma instintiva, para os gestos, as expressões faciais ${ }^{7}$, as falas de um personagem - com as respectivas reações dos outros -, do que para a roupa que os mesmos estejam vestindo ${ }^{8}$ ou para a cor dos objetos que o circundam.

Em Breaking Bad (2014), objeto de análise deste texto, ocorreu o inverso. Uma valorização da discursividade foi construída com o auxílio dos elementos de estilo do audiovisual, com robusta atenção para as cores. Por essa razão, quando Jesse Pinkman assassina outro personagem, o faz com uma camisa vermelha. Enquanto isso, Walter White vive cercado de azuis que remetem à coloração da droga que produz. Já Marie Schrader acredita ser uma integrante especial da sociedade, de uma espécie de realeza, e está encoberta de roxos. O seriado busca maior ativação sensorial dos espectadores, os inebria de excessos significantes, para além do mero contar de uma história. Breaking Bad (2014) faz parte de uma era inovadora da televisão, a era da narrativa televisual complexa.

Assim, em tempos de narrativas transmidiáticas, o consumo de séries televisivas tem grande atravessamento da cultura digital; seja pela narração textual de episódios no Twitter ${ }^{9}$, a consequente proliferação (e fuga) de spoilers; discussões com outras temporalidades; teorização sobre encaminhamentos e desdobramentos do enredo. De certa maneira, o formato estadunidense de temporadas com episódios semanais é articulado com o estabelecimento das redes digitais como ambientes de relacionamento para atores sociais ligados ao mercado, como o entretenimento, em que estes, direta ou indiretamente fomentam debates agendados de seus produtos (Ross 2008; Silva 2014). Contudo, destacamos que os próprios fãs se mobilizam em suas comunidades específicas, em lugares que, de alguma forma, tensionam a hierarquia de produção e recepção. Nesse sentido, Jenkins (2008; 2013) aponta para a produção de narrativas de entretenimento com as quais os fãs possam se envolver, produzindo enredos alternativos, influenciando no roteiro a partir de suas demandas, ou construindo

\footnotetext{
7 "[...] o feedback facial pode afetar o humor ou contribuir para a intensidade de um clima [...] O espectador pode efetivamente 'apanhar' parte da emoção que o personagem possa estar sentindo através de processos de mimetismo motor e contágio emocional" (Plantinga 2009, 126; tradução nossa). Carl Plantinga é um dos proponentes da junção das teorias estéticas do afeto com categorias do campo da psicologia, na escola de pensamento hoje assentada sobre a alcunha de cognitivismo. ${ }^{8}$ A atenção do espectador depende de diversos fatores, entre eles o interesse. Um estudante de moda poderia perfeitamente prestar mais atenção, ou tanto quanto, a ambos os elementos.

${ }^{9}$ Espécie de reaction espalhado, nos termos de Jenkins et. al (2013), em sites de redes sociais concomitante à transmissão dos episódios.
} 
conhecimento coletivo (Lévy 1992; 2000) a partir de suas complexidades. Neste artigo, nos concentramos neste último ponto.

Assim, temos como questão/objetivo principal verificar como estas especificidades das narrativas, cristalizadas no uso de cores em Breaking Bad (2014) - cujo consumo é envolto na cultura digital - são cristalizadas em chaves interpretativas de conversações em rede em torno do roxo enquanto excesso da personagem Marie Schrader, em centralidades de propostas de debates nos fóruns Quora e Reddit.

\section{A era da narrativa televisual complexa}

Certos jornalistas/críticos de televisão e pesquisadores da área costumam argumentar em favor de que viveríamos, na atualidade ${ }^{10}$, uma era de ouro ${ }^{11}$ das produções ficcionais televisivas, cujo sucesso e prestígio tem deixado na ribanceira o glamour outrora inalcançável de Hollywood. Em parte, se pode comentar brevemente sobre a avidez mordaz dos estúdios de cinema por uma maior garantia de lucratividade futura. Afinal, eles precisam prestar contas a Wall Street, uma vez que "os conglomerados de mídia estão atualmente em grande medida submetidos a uma lógica capitalista (financeirizada), particularmente através dos fundos de pensão, dos hedge funds [...] e essas complexas operações na bolsa são efetuadas (controladas) pelos bancos" (Martel 2013, 85). Desse modo, o cinema intensificou a produção de remakes - diversos dos quais advindos de produtos televisivos clássicos, como Batman (1968), Os Flintstones (1960), A Família Addams (1964), Missão: Impossível (1966), Scooby Doo (1969) e etc. "no intuito de abrir ou explorar novos mercados, ou (como no exemplo do Batman) fazer reviver e criar franquias crossmídia" (Verevis 2006, 38; tradução nossa). Tal quadro de exacerbado foco em repetições

parece uma função das estratégias conservadoras de produção e marketing de uma Hollywood contemporânea globalmente dominante (e, como a crítica a vê, artisticamente deficitária). Ou seja, desde meados da década de 1970, a indústria de cinema norteamericana investe - seja por 'atrofia criativa, dominação de conglomerados, timidez comercial ou todos os três ao mesmo tempo' - em várias estratégias de reciclagem de material. No caso dos remakes de televisão, os críticos se desesperam pela "pilhagem dos cofres de ideias de filmes da televisão', uma tendência que eles caracterizam como 'uma espécie de invasão de túmulos nos últimos dias'. [...] Missão: Impossível e outras propriedades de sucesso geraram não somente sequels [...] mas fizeram renascer séries de

\footnotetext{
${ }^{10}$ A atualidade depende da época em que os textos foram escritos, posto que todos defendem seu próprio tempo. Em geral, se concorda que os anos 1990 marcam ou o início ou o momento-chave/triunfante da virada.

11 Cf. Fabro \& Kist (2017) e Leslie (2017). Ademais das seguintes páginas: https://revistagalileu.globo.com/Revista/noticia/2017/09/era-de-ouro-da-tvseries-de-primeira-superam-industria-

cinematografica.html;https://oglobo.globo.com/cultura/revista-da-tv/era-deouro-das-series-comecou-quase-cinco-decadas-depois-do-inicio-do-genero-natelevisao-16955373. Acesso em 11.05.18.
} 
televisão, clipes musicais, trilhas de cinema, vídeo games, revistas em quadrinhos e outros produtos de marca (Verevis 2006, 38; tradução nossa).

A televisão, em geral, por outro lado, percorreu por um sistema, entre as décadas de 1960 e 1970, quando seus gêneros "foram definidos por suas fórmulas narrativas que eram, fundamentalmente, estáticas e repetitivas, enquanto apenas suas situações mudavam de semana para semana. Seu estilo ${ }^{12}$ era ainda mais estático do que a fórmula" (Caldwell 1995, 92; tradução e grifo nosso). Destarte, Hollywood viveria constantemente sob a tensão relacionada ao alcance do sucesso da bilheteria, tensão essa costumeiramente respondida através da feitura de mais remakes, enquanto "os executivos da televisão comercial (aberta) são pressionados tanto para gerar altas audiências a fim de assegurar mais dólares dos anunciantes, como também para garantir um contexto 'favorável à publicidade' que não aliene seus patrocinadores corporativos" (Kelson 2008, 47; tradução nossa). Tal contexto rigoroso constringiria a história a ser desenvolvida dentro de blocos invisíveis para o encaixe dos intervalos comerciais, conforme relata Ian Leslie (2017). Houve sobrevalorização de séries compostas por unidades narrativas mais concisas e autônomas, que pudessem ser vistas em qualquer ordem, o que por sua vez tornou prevalente os seriados do tipo procedural aqueles em que um arco dramático inteiro (começo, meio e fim de uma situação) ocorre dentro da hora proposta para sua exibição.

$\mathrm{Na}$ contracorrente, em 1972 se iniciaram as transmissões da HBO (Home Box Office), canal a cabo que indelevelmente buscou se afastar desses moldes em prol de uma produção diferenciada e dinâmica, cujo eventual sucesso - alçado especialmente por The Sopranos (1999-2006) - impactou o próprio modo de fazer séries ${ }^{13}$, o tanto que, nos últimos anos, "redes como ABC com Desperate Housewives e Lost, Fox com 24 Horas e Arrested Development, e NBC com The Office e My Name is Earl, todos trouxeram a fórmula HBO de 'qualidade' para o público mainstream" (Leverette et al 2008, 2; tradução nossa).

\footnotetext{
12 Estilo, aqui, se refere aos aspectos audiovisuais da produção. Eles eram enquadrados numa espécie de imobilidade, em modelo fechado e constante, posto que havia uma agenda de produção acelerada e verbas menores do que as ideais. Edgar Moura, diretor de fotografia de cinema e televisão, comenta que: "As comédias também têm um código: são feitas com pouco contraste. Primeiro, porque não seria agradável ver gente fazendo graça com o clima pesado resultante das sombras profundas. Segundo, porque é mais fácil e rápido fazer uma fotografia chapada, sem contraste, como dizem os iluminadores de televisão. E como ninguém vai ver comédia para ver efeitos de luz e sombra, faz-se só o que é necessário para que os atores sejam vistos. E pronto. É a mesma coisa com a luz das novelas. Luz por todo lado, para todos e para tudo" (Moura 2001, 191; grifo nosso).

13 "A complexidade não ultrapassou as formas convencionais na maioria das programações de televisão de hoje - ainda há muitas mais sitcoms e dramas convencionais no ar [...] (porém) há um número bastante difundido de programas que trabalha contra práticas narrativas convencionais" (Mittell 2015, loc. 90; tradução nossa).
} 
Como a HBO depende de assinantes em vez de anunciantes como sua principal fonte de receita, ela pode assumir riscos sem medo de frustrar patrocinadores. Não só que a HBO não precisa se preocupar com a possibilidade de ofender patrocinadores corporativos, mas também ela pode produzir plots que se desenvolvam lentamente em vez de seguirem em direção a mini clímaces antes das interrupções comerciais (Kelson 2008, 49; tradução nossa).

Tal liberdade ${ }^{14}$ constituiu um dos fatores basilares para o advento do que os pesquisadores Jason Mittell e Steven Johnson chamam de "complexidade narrativa"15. De forma diferente daquela descrita por Edgar Moura (2001), da rapidez esquemática da luz por todo lado, para todos e para tudo, a realização dessas produções ditas complexas - fotografia, arte, direção, edição, etc. - demandam uma certa engenhosidade detalhista que lhes torna os investimentos mais morosos e, por conseguinte, custosos. Em contrapartida, esses elementos extras que povoam suas histórias instigam os espectadores a ativamente buscarem mapeamentos temporários que pouco a pouco vão gerando ligamento lógico/coerência: "parte do prazer nessas narrativas de televisão modernas vem do trabalho cognitivo que você é forçado a desempenhar sobre seus detalhes. Se os escritores de repente deixassem cair um acúmulo de setas intermitentes no set, o show pareceria tedioso e simplório" (Johnson 2005, 77; tradução nossa).

É exatamente por essa razão que Breaking Bad (2014) é começado, em seu episódio inicial, sem maiores explicações, in medias res, com a já icônica e rememorada sequência de ação na qual o personagem principal, Walter White (Bryan Cranston), irrompe na tela, dirigindo desesperadamente um trailer, no meio do deserto, acompanhado de um homem desacordado ou possivelmente morto (Jesse Pinkman, Aaron Paul).

Após atolar o veículo contra um fosso em alta velocidade, ele sai vestindo somente sua cueca, com um revólver em punho, e

\footnotetext{
${ }^{14}$ À liberdade se soma o vácuo criativo deixado por Hollywood, alastrado de tal forma que a "TV é o lugar a seguir se você quiser fazer arte e dinheiro ao mesmo tempo. Paul Weitz, um roteirista e diretor cujos créditos incluem American Pie e Um Grande Garoto, está atualmente trabalhando na quarta temporada de Mozart in the Jungle para o Amazon Studios. 'Seu agente costumava dizer: 'Não faça TV, vai prejudicar sua carreira no cinema", lembra. 'Agora é o contrário"” (Leslie 2017; tradução e grifo nosso). Ainda: “'Atores que costumam fazer cinema estão indo para a TV porque é onde estão os papéis que não encontram em filmes', explica Debra Birnbaum, editora-executiva da revista de entretenimento Variety. Jane Fonda, Kevin Spacey, Anthony Hopkins, Nicole Kidman, Robert De Niro e Reese Witherspoon são apenas algumas das estrelas que escolheram brilhar na (televisão)" (Fabro \& Kist 2017).

15 "A complexidade narrativa se propõe a promover uma espécie de equivalência no tratamento da unidade da trama episódica e da evolução da narrativa central da série, num jogo de tensão entre os dois polos exercitado a cada episódio, que, por sua vez, oferece a experiência de uma trama completa e o prazer serial dos acontecimentos do porvir. [...] [O conceito abrange] ainda aspectos como ganchos narrativos falsos, digressões temporais, quebra de continuidade, tramas costuradas em paralelo que ‘colidem' entre si, e outros” (Neri 2015, 47-48).
} 
aguarda a lenta aproximação das sirenes dos carros policiais contra os quais ele aponta a arma. A cena é, em verdade, uma prolepse que reúne os elementos que circundarão a vida de White até o final da última temporada - a produção de drogas, o companheiro/aluno traficante, o medo e a violência, etc. "Programas de televisão complexos convidam à desorientação temporária e à confusão, permitindo que os telespectadores desenvolvam suas habilidades de compreensão através de visualização e envolvimento a longo prazo" (Mittell 2015, loc. 140; tradução nossa). A compreensão se efetua, em verdade, para a narratologia, através da leitura de signos distribuídos intencionalmente pelos criadores de forma desigual nas obras, em vista da ampliação dos horizontes atencionais. E são esses horizontes que permitirão escopos díspares de elos interpretativos aos diferentes espectadores, cujas conclusões serão invariavelmente partilhadas e discutidas entre eles. Em outras palavras, a complexidade fomenta o engajamento na resolução das charadas, temporárias ou definitivas, propostas pela engenhosidade elencada pelas mises-en-scène e roteiros dos shows complexos. Dessa maneira, a Internet adentra nessa equação, visto que as "audiências tendem a abraçar programas complexos em termos muito mais apaixonados e comprometidos do que a televisão mais convencional, usando essas séries como base para robustas culturas de fãs online ${ }^{16}$ e feedback ativo para a indústria de televisão" (Mittell 2015, loc. 100). A atuação do fandom de Breaking Bad (2014) na análise das funções efetuadas pelas cores será comentada mais adiante nesse trabalho. Antes, contudo, se faz necessário integrar e problematizar a teoria da complexidade narrativa com os conhecimentos preestabelecidos pela narratologia fílmica/audiovisual.

\section{Narrativa complexa e o excesso}

Os espectadores que escolhiam o que assistir ${ }^{17}$, e quando, eram mais propensos a exigir algo extraordinário e a prestar muita atenção. Este modo de exibição era uma notícia terrível para os canais que dependiam de um grande número de pessoas assistindo o que quer que estivesse no ar naquela noite - incluindo anúncios. "A economia da televisão estava implodindo por debaixo dela”, diz John Landgraf, ex-NBC, atual diretor-executivo do canal FX da Fox. "As pessoas não assistiam as repetições, que era como os canais ganhavam dinheiro". Se um público grande e desatento era mais valioso para os canais do que um pequeno e leal, então, para a HBO, era o inverso (Leslie 2017; tradução e grifo nosso).

A fórmula $\mathrm{HBO}$ de qualidade, citada por Leverette, recompensa a atenção dos espectadores. Atenção, exatamente, a quê? Conforme

\footnotetext{
16 "As comunidades de fãs online podem muito bem ser algumas das versões mais plenamente realizadas da cosmopedia de Lévy, grupos expansivos auto organizados focados na produção, debate e circulação coletiva de significados, interpretações e fantasias em resposta a vários artefatos da cultura popular contemporânea" (Jenkins 2006, 137; tradução nossa).

${ }^{17}$ Referência primeiramente aos DVD e, depois, ao on demand na web.
} 
discussão aventada anteriormente neste texto, suporá corretamente o leitor que tenha identificado que a resposta será: aos pormenores narrativos. Todavia, o que significa pormenor narrativo? O pormenor ou excesso é parte daquilo que não está a serviço imediato da evolução dramática que ocorre no percurso da história, um dos dois pilares fundamentais da teoria narratológica.

Tomando a poética como uma disciplina racionalista, podemos perguntar, como faz o linguista sobre a linguagem: quais são os componentes necessários - e somente aqueles - de uma narrativa? A teoria estruturalista argumenta que cada narrativa tem duas partes: uma história (histoire), o conteúdo ou a corrente de eventos (ações, acontecimentos), mais o que pode ser chamado de existentes (personagens, itens de configuração); e um discurso (discours), isto é, a expressão, o meio pelo qual o conteúdo é comunicado. Em termos simples, a história é o que é retratado em uma narrativa, e o discurso o como (Chatman 1978, 19; tradução nossa, grifos do autor).

Deste modo, Chatman define a história como a portadora do conhecimento declarativo, ou o conteúdo. Enquanto o discurso é o vetor do conhecimento procedural, ou a expressão do o quê. A história tem uma estrutura que não pertence ao meio que a expressa, é virtual ou transponível nas palavras de Chatman. Romeu e Julieta de Shakespeare pode ser adaptado como um funk, como um filme, como uma ópera, etc., sem que a informação dos elementos sequenciais (o encontro, o amor proibido, a morte, etc.) seja perdida ${ }^{18}$. Em outras palavras, o discurso materializa ${ }^{19}$ a virtualidade da história em uma sucessão específica de acontecimentos/ações/transformações. Todavia, não só lhe dá encadeamento causal - o ato X causa o Y que causa o Z, etc. -, como organiza e seleciona quais partes serão ditas e quais omitidas. Ademais, é via discurso que será definido, dentro de cada parte, a quantidade de aspectos a serem trabalhados e suas correlações.

Dessa maneira, a diferença entre um produto voltado à desatenção, da célere luz para tudo, e outro calcado em complexidade, se conforma num movimento do exercício criativo, durante a produção, da história para o discurso. Esse movimento está na contramão daquilo que se tornou corriqueiro tanto em Hollywood

\footnotetext{
${ }^{18}$ Cf. Anchieta (2017), para mais pormenores sobre a distinção entre história e discurso.

19 "O enredo ou história é o material que é apresentado, ordenado a partir de um certo ponto de vista pelo discurso (diferentes versões da 'mesma história'). Mas o próprio enredo já é uma configuração de acontecimentos. Um enredo pode tornar um casamento o final feliz da história ou o começo de uma história - ou pode fazer dele uma reviravolta no meio. O que os leitores realmente encontram, entretanto, é o discurso de um texto: o enredo é algo que os leitores inferem a partir do texto, e a ideia dos acontecimentos elementares a partir dos quais esse enredo foi formado é também uma inferência ou construção do leitor. Se falamos de acontecimentos que foram configurados num enredo, é para realçar o significado e a organização do enredo" (Culler 1999, 87; grifo do autor).
} 
quanto na televisão ${ }^{20}$, onde o interesse está, em geral, no acompanhamento global da ação (Bordwell 1985, 157). Tal fato acaba por acostumar os espectadores, em geral, a desperceber aquilo que não está explicitamente relacionado com o encadeamento entre causas e efeitos. Como veremos adiante, esses elementos podem servir a diversos fins e potencializar diversas interpretações no público consumidor. De forma concomitante, eles não são vitais para o avanço da intriga proposta - "todo elemento estilístico pode servir ao mesmo tempo para contribuir com (o avanço da) narrativa e distrair a nossa percepção dela" (Thompson 1977, 57). Tal é a definição que Kristin Thompson configura ao excesso (também supracitado como detalhe): o discurso audiovisual espalha o excesso pelos quadros para que ele venha a, possivelmente, chamar a atenção de alguém, posto que ele também distribui informação narrativa. E para introduzir seu conceito, de estética operacional - aquela que estaria presente na televisão complexa, Mittell invoca precisamente o excesso, adjetivando-o de qualidade barroca:

a televisão complexa oferece uma outra atração: o efeito especial narrativo. Este dispositivo ocorre quando um programa flexiona seus músculos de contar histórias para confundir e surpreender um espectador [...] [como na] revelação dos flashforwards em Lost ("Through the Looking Glass"), ou a incorporação do personagem principal Dawn, na quinta temporada de Buffy, com a fina costura de um backstory. Esses momentos de espetáculo empurram a estética operacional para o primeiro plano, chamando a atenção para a construção da narração, e nos clamam para que nos maravilhemos com a forma como os escritores a orquestraram; muitas vezes se renuncia a um realismo estrito em troca de uma qualidade barroca, formalmente consciente, em que observamos o processo de narração como uma máquina em vez de nos engajarmos em sua diegese (Mittell 2015, loc. 121-3; tradução nossa e grifos do autor).

As "narrativas (audiovisuais) estabelecem seu espaço diegético, permitindo que o espectador gere uma leitura consistente aos marcadores de uma continuidade temporal e uma contiguidade espacial (apesar da descontinuidade 'real' e da não-contiguidade)" (Elsaesser \& Hagener 2015, 199). Cabe reafirmar que tanto esses espaços quanto os tempos narrativos estarão organizados, via discurso/estilo, em quadros sucessivos preenchidos de objetos e estímulos que lá foram cuidadosamente inseridos a fim de serem notados em suas relações intencionais/designadas com outros objetos e estímulos presentes na narrativa (Branigan 2006, 105). Ademais, "há um contínuo praticamente infinito de pormenores imagináveis entre os incidentes (mostrados), que normalmente não serão expressos, mas que poderiam ser. $\mathrm{O}$ autor seleciona os eventos que ele sente

${ }^{20}$ Ponderação de Jorge Furtado: "A televisão tem o público mais desatento do mundo. O cara atende telefone, começa a ver pela metade, ou para de ver antes do final. Por isso a televisão é tagarela, não cala a boca nunca, para (tentar) chamar atenção o tempo todo". Disponível em < http://revistaepoca.globo.com/Epoca/0,6993,EPT550012-1661,00.html >. Acesso em 03.02.18. 
serem suficientes para provocar o sentido necessário do continuum" (Chatman 1978, 30; tradução nossa e grifo do autor).

Por se tratar de característica secundária, a cor é costumeiramente considerada como excesso ou pormenor, parte daquilo que inunda os planos - seja nas vestimentas, na luz, nos cenários, etc. - sem ter, a priori, função essencial para o desenvolvimento do enredo ${ }^{21}$. Numa estética operacional, focada no aumento da criatividade dos usos dos recursos de estilo, a gestão artística do uso da cor pode torná-la, por exemplo: i) elemento caracterizador: Vince Gilligan comentou numa entrevista para revista Vulture $^{22}$, em 2011: “A cor é importante para Breaking Bad; nós sempre tentamos pensar nesses termos. Nós sempre tentamos pensar na cor em que um personagem está vestido, no sentido de que representa em algum nível seu estado de espírito"; ii) elemento informativo: "O vermelho é cor da raiva (ocasionalmente fatal) de Jessie, enquanto seus tons de usuário de drogas em recuperação são mais monótonas e subjugadas" (Larue 2013; tradução nossa) ${ }^{23}$. Ou seja, se Jessie está rodeado de vermelho, existe indicação de que ele irá cometer algum ato de violência, potencialmente mortífero, como quando assassina Gale (David Costabile), a sangue frio, no último episódio da terceira temporada, Full Measure, exibido em 2010.

Aquele pormenor que compõe o evento do enredo vive à espreita de ser encontrado e decodificado, e sua descoberta gera um prazer $^{24}$ que "põe leitor e autor em relação através do texto. As escolhas do último provocam, guiam e de certa forma, também frustram o primeiro" (Lesnovski 2014, 31). Ratificando Mittell, é no desvendamento dos engenhos narrativos que se encontra o deleite da estética operacional. E é no compartilhamento dessa satisfação que os fãs concretizam sua atividade: "Os fãs informam uns aos outros sobre o histórico do programa ou desenvolvimentos recentes que alguns podem ter perdido. A comunidade de fãs agrupa seu conhecimento porque nenhum fã pode conhecer tudo o que é necessário para a

${ }^{21}$ Basta um breve exercício de imaginação para confirmar isso. Se Breaking Bad (2014) fosse exibido totalmente desprovido de cores, enquanto história, entendida como relações de causa e efeito que evoluem para um clímax final, o que haveria, nesses termos, de diferente? Não que a cor não tenha capacidades informativas ou emotivas. David Batchelor argumenta: "Ao ser desnecessária, a cor encontra um lugar no além do necessário [...] a cor é única em sua inutilidade. É inútil, mas não insignificante [...] tem efeitos intensos e muito evidentes sobre aqueles que a encontram" (2014, 32; tradução nossa).

22 Tradução nossa. Disponível em https://www.vulture.com/2011/05/vince_gilligan_showrunner_tran.html>.

Acesso em 10.12.17.

${ }^{23}$ LaRue desenvolveu um gráfico que dispõe em seu eixo horizontal uma linha do tempo das cinco temporadas e no vertical a cor tônica que circunda cada personagem, em cada episódio. Gráfico completo disponível em: < http://www.slate.com/content/dam/slate/blogs/browbeat/2013/08/12/breakin gbad_color.jpg >. Acesso em 25.08.17.

24 "O prazer da narrativa se vincula ao desejo. Os enredos falam do desejo e do que acontece com ele, mas o movimento da própria narrativa é impulsionado pelo desejo sob a forma de 'epistemofilia', um desejo de saber: queremos descobrir segredos, saber o final, encontrar a verdade” (Culler 1999, 92-93). 
apreciação plena da série" (Jenkins 2006, 139; tradução nossa). Assim, como próprio Jenkins discorre, fãs constroem tanto conhecimento quanto adquirem capitais de distinção nas comunidades de gosto.

\section{Metodologias de trabalho}

A observação composicional (Rose 2001,38 ) se pode estabelecer pelo olhar atento à "composicionalidade" da imagem ela-mesma. É um ato decompor as operações realizadas na geração da imagem, na busca de gestos - uma vez que os próprios são os germes da intencionalidade estética. É um desmembrar em questões: quanto tempo dura esse plano? Qual o enquadramento dele? Esse plano se coliga com qual outro, ou qual sequência? Qual personagem ou objeto é figurado? Há algo/alguém em proeminência? Qual a relação entre eles? É um conjunto virtualmente infinito de indagações que deve ser contingenciado em um recorte produtivo que meça em qual medida tais gestos são capazes de programar efeitos nos espectadores, conforme explica o pesquisador Wilson Gomes ${ }^{25}$, sobre a potência estética das imagens em movimento. Nosso recorte se encontra nos elementos coloridos que são figurados com proeminência pelos planos de Breaking Bad (2014), como os vermelhos que se anunciam com força em determinados momentos que precedem extrema violência; e/ou que se repetem em demasia: tal qual a caracterização da personagem de Marie Schrader com um tom praticamente monotemático de roxo.

A partir de Colonna (2010), Silva (2014) chama a atenção para o investimento não apenas em mise-en-scène, mas de textos atraentes para públicos com potencial de dispersão em ambientes de apreciação com outros dispositivos. Aqui, no sentido de estratégia mercadológicas, estes dispositivos, como gadgets, embora possam inicialmente ser, e ainda o serem, instrumentos potencializadores de dispersão e desinteresse pelo consumo, são ressignificados como dispositivos de consumo do produto, seja por apropriações dos fãs das séries ou por estímulo de produtores. Silva (Gomes 2014, 246) aponta que "vêm sendo desenvolvidas diversas estratégias para estimular o espectador a comentar nas redes sociais durante a exibição dos episódios, como a presença da hashtag da série no canto da tela, ou mesmo a participação de membros da equipe e dos atores comentando com os seguidores no Twitter sobre o desenrolar da narrativa”. Este fomento é o que Ross (2008) designa como teleparticipação. Embora mais vinculado à temporalidade de exibição, nos permite pensar como parte do universo de construção de conhecimento coletivo sobre estes produtos.

Estas comunidades estão cristalizadas desde grandes marcos de séries, como a Lostpedia de Lost, e diversos outros wikis sobre séries,

25 "Os modos de estruturação do filme não funcionam como camadas justapostas; o filme é, ele mesmo, uma composição na qual são sintetizados várias composições e usos dos elementos e materiais. O filme, como um todo, é a programação de efeitos, a logística que direciona e coordena as estratégias fundamentais e os usos de seus recursos elementares" (Gomes 2004, 101). 
filmes etc., a fóruns que funcionam em outras lógicas, discussões pontuais dispersas ou centralizadas em ambientes com escopos de possibilidades mais abertos, como fóruns gerais da Internet, tal qual Quora e Reddit que delimitamos nesta pesquisa. A partir da inteligência coletiva de Lévy, em que o máximo de informações e consequente produção de conhecimento sobre algo é obtido através de pequenas contribuições individuais, a pesquisa de Jenkins (2008) foca em redes de revelação de produtos midiáticos, seja na busca por spoilers de enredos já gravados, seja para expandir universos canônicos ou comunidades interpretativas para aquilo que está sendo dito, apontando que "investigar como essas comunidades de conhecimento funcionam pode nos ajudar a compreender melhor a natureza social do consumo contemporâneo de mídia” (Jenkins 2008, 47).

Assim, somado a intepretações algorítmicas, não é à toa que a cada episódio de Game of Thrones (2017) os feeds dos usuários de sites de redes sociais pareçam ter apenas publicações sobre a série. Contudo, estas narrativas, via de regra, parecem mais atreladas aos desenrolares imediatos do enredo. A mobilização afetiva em torno de camadas de interpretação de que tratamos aqui parecem pertencer a outras temporalidades, que requerem maior precisão de raciocínio e formulação do que as reações pontuais ao que é apresentado na tela.

John Caldwell argumenta que as práticas do excesso foram sendo apresentadas aos espectadores difusamente ao longo das décadas. Dessa maneira, "muitos shows começaram a funcionar, não apenas tornando sua mise-en-scène mais excessiva, mas tornando seu comportamento de apresentação mais excessivo e sofisticado" (1995, 92; tradução nossa e grifo do autor). The Sopranos (2014) é considerado um marco porque combinou uma variada gama dessas técnicas num só lugar e, ao mesmo tempo, conquistou amplo sucesso de audiência e crítica ${ }^{26}$. Quanto mais o discurso narrativo, aqui estilo audiovisual e/ou roteiro, é adicionado de camadas de excessos, mais aspectos se abarrotam na disputa pela zona de atenção dos espectadores. E não basta estar atento, posto que ainda é preciso trabalhar sobre as informações para conectá-las e delas extrair sentido: "uma maneira de responder aos desafios interpretativos de narrativas não naturais ${ }^{27}$ é criar novos parâmetros cognitivos através da reorganização e/ou da recombinação de quadros e roteiros existentes" (Alber et al 2010, 118; tradução nossa), ou seja, partir de múltiplos exercícios interpretativos prévios tomados de outros produtos audiovisuais, que naturalmente causaram uma espécie de "treinagem cognitiva" (Johnson 2005, 14). Para além do acúmulo de

\footnotetext{
${ }^{26}$ A televisão aberta já havia inovado, quase dez anos antes, com a exibição de duas temporadas de Twin Peaks (2017), de David Lynch. No meio do segundo ano, após a resolução do mote principal da história (quem matou Laura Palmer?), houve brutal queda de audiência, que acabou por levar a ABC a cancelar a produção do show. ${ }^{27}$ Narrativas inseridas em mundos inverossímeis ou transmitidas dessa maneira (discurso). Por exemplo, no mundo real do dia-a-dia ou mesmo em obras nãocomplexas, as cores não seguem uma lógica de sentido padronizado. Elas simplesmente existem em proliferação caótica.
} 
horas de experiência própria, fator natural, a era da web ainda adiciona a possibilidade de debate, ao alcance dos dedos, com o mundo inteiro, em tempo real, dos inúmeros pormenores que continuamente se apresentam pelo desenrolar da história. "A estética operacional está em exibição nas dissecações das técnicas empregadas pela televisão complexa realizadas em fóruns de fãs online [...] sugerindo o prazer de desvendar as operações da mecânica narrativa" (Mittell 2015, loc. 120; tradução nossa).

Desta forma, no intuito de compreender como se dão as dinâmicas conversacionais em rede num sentido de constituição de possíveis interpretações ou reorganizações para estas camadas de excesso em Breaking Bad (2014), utilizamos inscrições na Análise de Construção e Sentidos em Redes Digitais ${ }^{28}$, operacionalizadas através de a) mapeamento de casos ou conversações em redes digitais (no sentido de construir uma problematização e delimitar um corpus de pesquisa); b) categorização (observações de desdobramentos conversacionais são sistematizadas através de núcleos de discursos similares e recebem uma designação); c) inferências (atribui-se reflexões em torno das interpretações).

Em nossa proposta, nos atentaremos mais especificamente aqui a conversações entre (potenciais) fãs de Breaking Bad (2014) sobre discussões acerca de Marie Schrader (Betsy Brandt) através de uma incursão nos sites/fóruns Quora ${ }^{29}$ e Reddit $^{30}$. Marie Schrader (Imagem 01) é irmã de Skyler White - por conseguinte, cunhada de Walter White, personagem principal da série. É casada com um agente da $\mathrm{DEA}^{31}$, Hank Schrader, também cunhado de Walter. Ao longo do seriado, sua função costuma se resumir, em geral, a prover suporte emocional tanto para a irmã quanto para o marido, ao passo que cuida

$28 \mathrm{O}$ método, em perspectiva semiótica, é proposto pelo grupo de pesquisa LIC (Laboratório de Investigação do Ciberacontecimento), do Programa de PósGraduação e Comunicação da Universidade do Vale do RIo dos Sinos e liderado pelo Prof. Dr. Ronaldo Henn (2014).

${ }^{29}$ Quora é um site de perguntas e respostas fundado por dois ex-funcionários do Facebook. Diferente de plataformas semelhantes, como o Yahoo Respostas, também mantido por sua comunidade de usuários na proposição, resolução e edição de questionamentos, o Quora, em tese, exige que seus usuários se autoapresentem com seus nomes civis - ou seja, não é possível utilizar pseudônimos, recurso recorrente na cultura digital. Embora não haja verificação de dados identitários, usuários podem ser denunciados por outros usuários e a práxis tem a intenção de conferir maior credibilidade às respostas e debates. <https://quora.com>

${ }^{30} \mathrm{Um}$ site operacionalizado como um grande fórum, fundado em 2005, avaliado em 2017 em 1,8 bilhões de dólares, com mais de 500 milhões de visitantes por mês - é o sexto site mais visitado da internet. Elaborada para funcionar de forma colaborativa, os usuários da plataforma votam nos tópicos que consideram mais ou menos interessantes, tal como BuzzFeed e 9gag são utilizados para captura de conteúdos para outras mídias sociais, assim como um indicador relevante do que as pessoas estão interessadas em consumir e conversar sobre o assunto na Internet. Seu nome vem de um jogo de palavras "read it" (leia isso). <https://www.reddit.com>.

${ }^{31}$ Agência policial dos EUA especializada no combate às drogas. Em inglês, a sigla corresponde a Drug Enforcement Administration. A DEA é uma agência real, cuja existência e funcionamento o seriado adaptou livremente às suas necessidades narrativas através de sua licença poética. 
de seus próprios dilemas - por exemplo, ela sofre de cleptomania. Nossa escolha pelo Quora e Reddit dá-se nas a partir de suas características de discussão (em inglês) de diversos assuntos propostos por seus usuários, a representatividade dos mesmos como chanceladores de debates em rede e referência para as discussões em círculos mais fechados de comunidades de fãs, além de os dados estarem disponíveis sem mediação de qualquer tipo de cadastro -, caracterizando sistemas abertos (Fragoso; Recuero \& Amaral 2013) e dados públicos (Elm 2009).

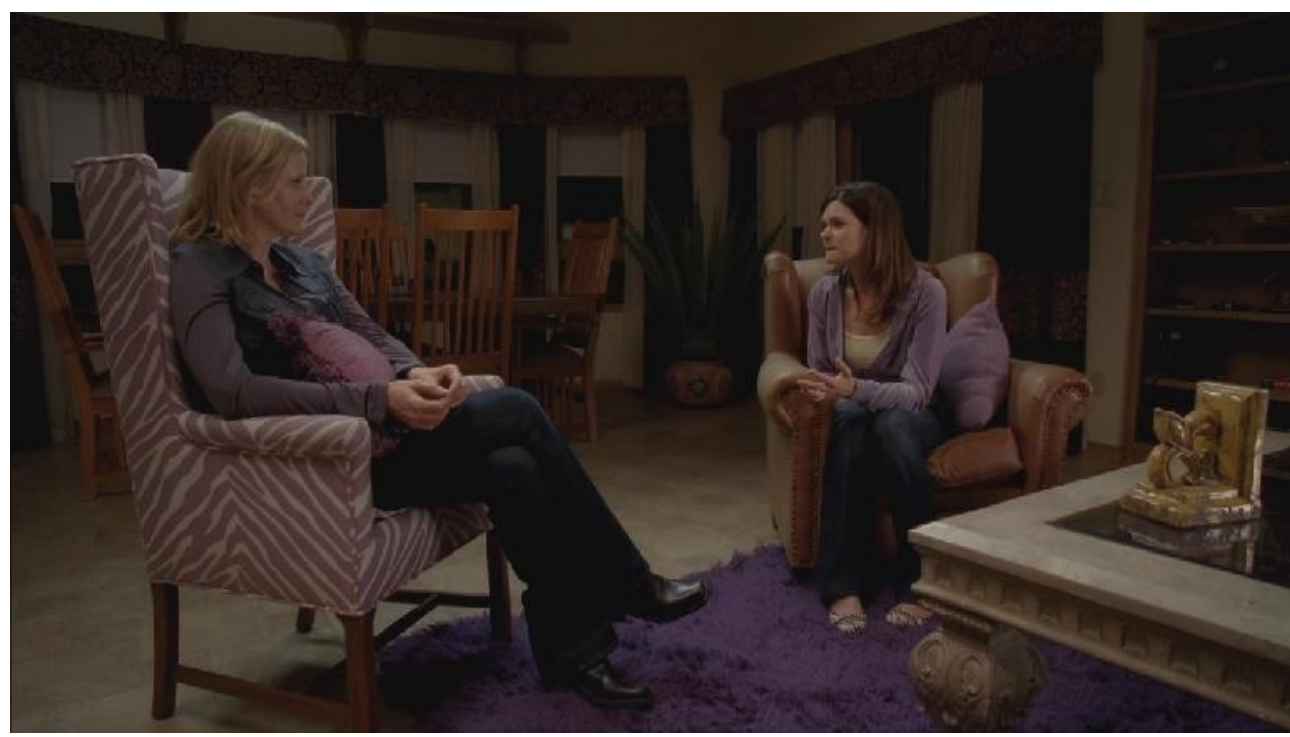

Figura 1: Fotograma de Breaking Bad, com Skyler White (Anna Gunn) e a irmã Marie Schrader (Betsy Brandt), no episódio "Gliding Over All" (5.08). ( ) High Bridge Productions \& Gran Via Productions.

Assim, selecionados os dois sites, delimitamos buscas com as seguintes palavras chave: marie, breaking bad, purple - esta última, já oriunda da crescente discussão online sobre as cores de roupas utilizadas pelos personagens e em inglês, devido à hegemonia do idioma nos dois sites. Dos resultados obtidos, selecionamos três tópicos e seus respectivos desdobramentos conversacionais para análise: Why does Hank's wife in Breaking Bad wear purple all the time? ${ }^{32}$ (conversações entre outubro de 2014 e março 2018), Is there any reason why Marie in Breaking Bad has everything purple? ${ }^{33}$ (conversações entre janeiro 2012 e janeiro 2017) e Breaking Bad: Why does Marie always wear purple? ${ }^{34}$ (conversações ocorridas há quatro anos $)^{35}$, configurando a primeira etapa e início da segunda, que discutiremos a partir de agora. A partir do que se discute online sobre

\footnotetext{
${ }^{32}$ www.quora.com/Why-does-Hanks-wife-in-Breaking-Bad-wear-purple-all-thetime

${ }^{33}$ www.quora.com/Is-there-any-reason-why-Marie-in-Breaking-Bad-haseverything-purple

${ }^{34}$ www.reddit.com/r/FanTheories/comments/1n5ej1/request_breaking_bad_wh y_does_marie_always_wear/

35 O Reddit não informa precisamente mês e ano em que as publicações são realizadas.
} 
Marie, o roxo como excesso e da argumentação apresentada ao longo deste artigo ${ }^{36}$, propomos cinco categorias de comentários que, em grande parte, entendemos corroborar esta argumentação, mas também tensionam minimamente estas e determinadas formulações canônicas dos fãs da série - esperamos cumprir a etapa reflexiva do método proposto, a partir de nossa sistematização e considerações em torno do processo.

\section{Fãs e a inteligibilidade do complexo}

A) Caracterização: $\mathrm{Na}$ reportagem supracitada com o criador do seriado, Vince Gilligan, o entrevistador o questiona sobre Marie: "Por que [tanto] roxo?", "Bem, a Marie diria que o roxo é a cor da realeza" ${ }^{37}$. Tal afirmação é historicamente correta, uma vez que antes da revolução química das cores ocorrida no século XIX ${ }^{38}$, era do muco glandular de moluscos que se retirava a matéria-prima para a produção da "cor exuberante conhecida como púrpura tíria. O processo era tão árduo e caro que o roxo estava reservado para as vestes dos reis desde os tempos romanos" (Blaszczyk 2012, 22; tradução nossa). Conclusões similares e também interpretações diversas são apontadas por fãs na imagem 02 , abaixo.

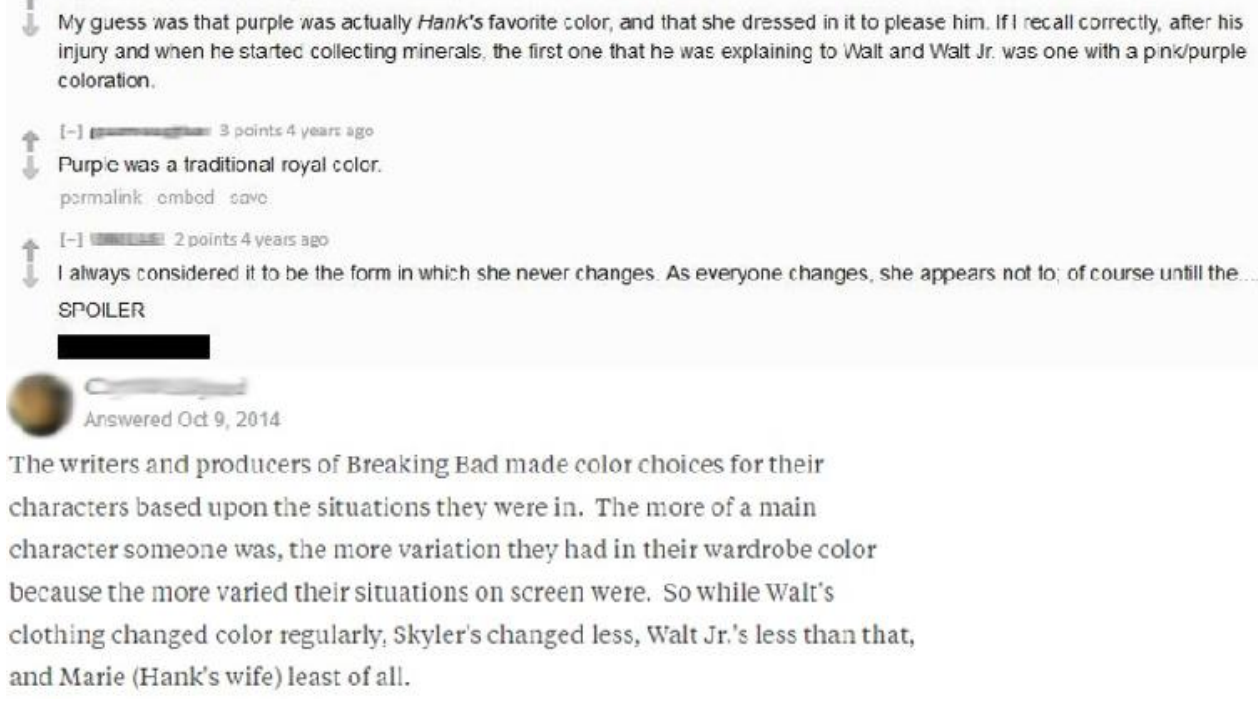

Figura 2: Comentários de fãs sobre o uso exagerado de roxo por Marie e sobre as trocas de cores e roupas dos personagens. Note que a faixa preta se trata de texto escondido, visto que é um spoiler (ele será comentado na subseção da inferência). (c) Reddit.

\footnotetext{
${ }^{36}$ Rememorando, a saber: que os produtos televisivos têm trabalhado com uma abundância de detalhes que tornam a narrativa mais densa, bela e desafiadora, portanto mais prazerosa para acompanhar e compartir; não obstante o fato deles serem integralmente dispensáveis ao avanço do conhecimento declarativo em termos narratológicos.

${ }^{37}$ Cf. nota 14.

${ }^{38}$ Cf. Taussig (2009).
} 
O terceiro comentário aponta para o fato de que a cor se movimenta, de que ela se altera na tela, em termos físicos, e se altera para todos os personagens - o que pode ser constatado visualmente pelo gráfico de cores desenvolvido por John Larue. Para todos, com a patente exceção de Marie, a não ser por relances breves: "O que faz com que Marie seja digna de nota não é que ela se vista toda de roxo, todo o tempo. Em vez disso, são ocasiões muito raras quando ela não usa roxo que praticamente gritam ao espectador. Por exemplo, ela usa preto quando sua cleptomania piora" (Larue 2013; tradução nossa e grifo do autor). Essa percepção também é corroborada por comentários que indicam não só pelo espanto de quando Marie não está usando roxo, mas por sua personagem em relação ao enredo - no qual os protagonistas são os que mais alteram suas cores (imagem 02). Resta evidente, então, que as interpretações podem convergir ou divergir entre os fãs. A análise do segundo é consoante com a do criador da obra, ao passo que a do terceiro concorda com o fã-repórter e designer John LaRue.

B) Inferência: O terceiro comentário da imagem 02 faz alusão a um spoiler e por isso tem parte do texto escondido. O fato é o assassinato de Hank, marido de Marie, durante o décimo-quarto episódio da quinta temporada, Ozymandias (2013). Conforme teoria de Culler, aquilo que ele nomeia de epistemofilia ${ }^{39}$ é o prazer que todo leitor/espectador possui ao efetuar descobertas temporárias no transcorrer do percurso e, do mesmo modo, chegar nas revelações finais do clímax. Esse gozo nos prende na história e nos faz querer saber mais e, se possível, logo. Assim, tentamos antecipar o que está por vir. Também buscamos remodelar o entendimento de obras já lidas ou vistas à luz de novos conhecimentos. A partir de Rabid Dog (2013), antepenúltimo episódio antes da morte de Hank, Marie passa a se vestir de preto. Israel Pedrosa explica que, culturalmente, o preto está estigmatizado com "o caos, o nada, o céu noturno, as trevas terrestres, $o$ mal, a angústia, a tristeza, o inconsciente $e$ a morte, o preto é o símbolo maior da frustração e da impossibilidade" (2009, 133, grifo nosso). Se LaRue tem razão e nos gritam os momentos em que Marie não se veste de roxo, então, nossa epistemofilia se ativa - para aqueles que tenham notado essa nuance, evidentemente -, e passamos a tentar descobrir a causa dessa alteração.

${ }^{39}$ Cf. nota 16. 


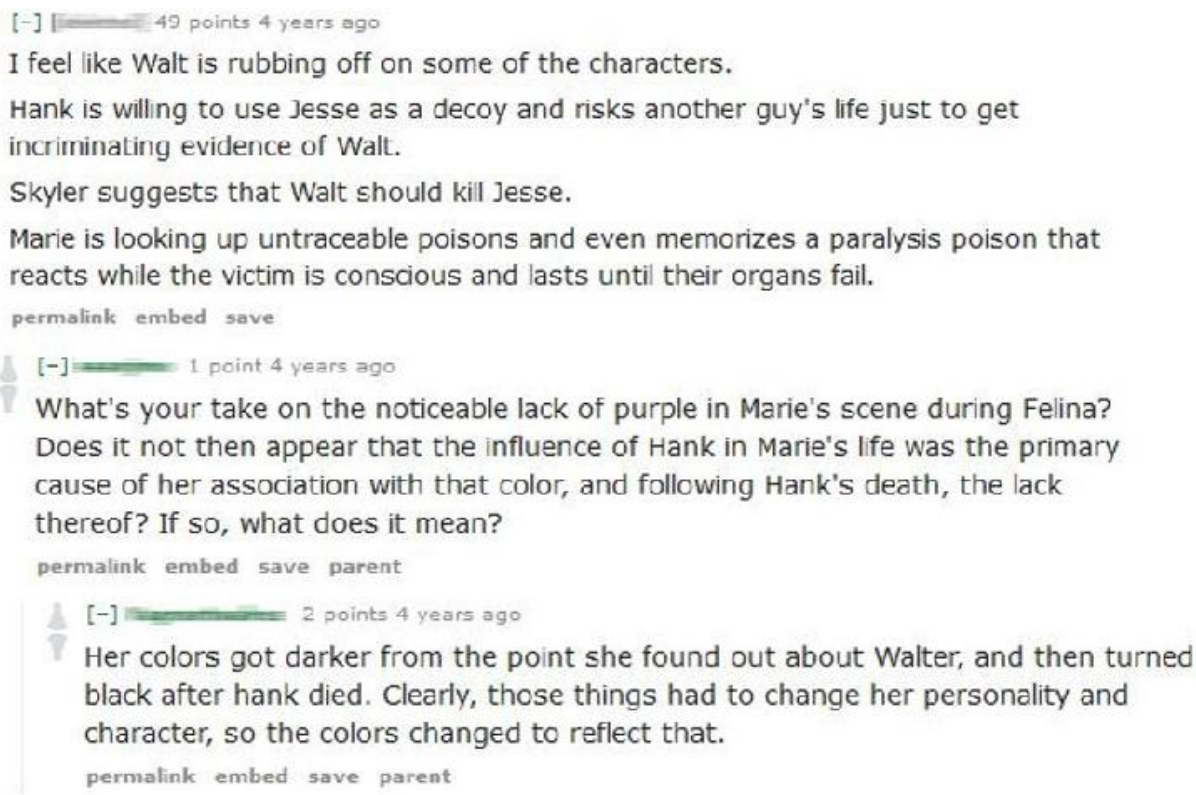

Figura 3: Comentários de fãs sobre os atos de Marie em "Rabid Dog” (5.12) e sobre o uso da cor preta pela mesma. (C) Reddit.

Ocorre que em Rabid Dog (2013) as pistas trazidas pelo excesso se apresentam nebulosas, uma vez que Marie aparece conversando com seu psicólogo sobre venenos não rastreáveis, um salto para uma personagem que outrora funcionava como apoio emocional aos outros. Suas vestimentas se mantêm pretas, basicamente, até o final de Breaking Bad (2014). Ao mesmo tempo que não fazem o enredo caminhar, os excessos gestam microcosmos de sentidos que atiçam a curiosidade interpretativa e, dessa maneira, colocam os espectadoresfãs em debate contínuo, que não se exaure mesmo havendo 'confirmação' ou 'negação' de certas análises por parte dos criadores das obras, uma vez que o ato de leitura é também um gesto afetivo e pessoal.

C) Roxo como signo de antecipação: similar à categoria de Adivinhação, esta designa as conversações que entendem a cor e suas tonalidade não a partir de evolução de personagem ou trama, de forma gradativa, mas de acontecimentos imediatos nos episódios. Tal qual as laranjas em The Godfather (1972), indicando um assassinato, ou objetos vermelhos em The Sixth Sense (1999), indiciando alguém morto na cena, neste caso, o roxo indicaria que alguma materialidade presente não foi obtida de forma $100 \%$ lícita ou que quem a obteve não está com consciência limpa por essa aquisição. Aqui a cor seria mais singular e menos uma construção perene de personagem, como no caso de Marie, além de não se restringir apenas a ela. 
Answered Dec 1, 2016

I don't why they choose purple, but usually when purple appears anywhere but with Marie, some is stealing, or taking something from someone else. Jessie pinkmans parents lawyer wears a purple tie when he takes Jessie's house is an example. The purple p.t. Cruiser is another good example, skylar took his charger and replaced it with the purple cruiser. there are other examples as well.

I would think Marie's purple assignment had something to do with her being Skyler's "spoiled bitch sister" who shoplifts a tiara and is protected from her kleptomania by her knight in DEA garb. She is a quintessential princess and purple is the colour of royalty.

983 Views - View Upvoters

\begin{abstract}
8 points 4 years aro $\cdot$ edited 4 vears ago
My guess was that purple was actually Honk's favorite color, and that she dressed in it to please him. If I recall correctly. after his injury and when he started collesting minerals, the first one that he was explaining to Walt and Walt jr. was one with a pink/purple coloration.
\end{abstract}

Figura 4: Comentários de fãs relacionando cores a singularidades de acontecimentos. (C) Reddit.

D) Indicação de sua vinculação com Hank: esta categoria abarca as interpretações de que o roxo demonstra sua vinculação com o marido e a proteção do mesmo para perigos alheios e os ocasionados por ela mesma (imagem 04). Hank, agente da DEA, ou o cavaleiro que protege a realeza (que veste roxo), além de ser, em verdade, a cor favorita de Hank, e não dela. Assim, na vindoura ausência de Hank, quando este parte em sua jornada final para capturar Walter e sendo assassinado, Marie já passa a vestir preto.

E) Camadas do acaso: neste núcleo, embora seja possível argumentar, através do discurso dos produtores e uma breve análise indicial retrospectiva da série, o padrão teria sido reconhecido posteriormente, ao acaso, e não elaborado como elemento intencional. Assim, na interseção com a caracterização dos personagens, no caso de Marie, representaria suas particularidades e problemas psicológicos.

\title{
Considerações finais
}

A era de ouro da televisão traz consigo um ciclo virtuoso, em que as "novas tecnologias fornecem a infraestrutura de informação necessária para manter uma forma mais rica de conteúdo de televisão, enquanto esses programas recompensam as competências aprimoradas das comunidades de fãs" (Jenkins 2006, 145; tradução nossa). É passível de afirmação, portanto, que os fãs desbravam aquilo que ficou estabelecido no plano poético, na sala de criação - conforme fala de Gilligan -,sendo assim capazes de tanto continuarem fixados no clímax, pela epistemofilia (o que acontecerá no final? ${ }^{40}$ ), quanto de

${ }^{40} \mathrm{O}$ ato dos fãs de tentar antecipar o desfecho de suas obras queridas a partir do que outrora foi considerado como elemento secundário das narrativas reforça, precisamente, a importância de pesquisá-lo. Fãs-cientistas se utilizam de algoritmos para tentar descobrir quem será o próximo personagem a ser morto em Game of 
explorarem as sutilezas que aprofundam nossa relação com a riqueza de pormenores trazidos a reboque pela televisão complexa.

Isso permite se manterem renovadamente encantados a cada visita à obra, posto que nela verão outras relações que já estavam lá indicadas, embora tenham passado a priori despercebidas para a maioria dos espectadores. É graças à atuação interpretativa de milhares fãs como LaRue, por exemplo, que se encontram na web amplos e diversos compêndios de conhecimento sobre tanto as generalidades da história quanto as minúcias do discurso das produções televisivas.

A partir do corpus que propomos, percebemos que as chaves interpretativas nas conversações são operacionalizadas, tanto assumindo o direcionamento dado por quem produz a série (em que Marie pensaria que roxo é da realeza), quanto negando-o (sendo o mais extremo o comentário que aponta para a não intencionalidade inicial de vincular Marie à cor roxa). Contudo, destacamos que a fala dos produtores é apropriada pelos fãs como signo de autoridade, o que parece se complementar com os exercícios de previsão, em que se tenta aproximar, assim como Gilligan afirma o que Marie pensaria do que o próprio produtor da série pensaria para o futuro do enredo.

Finalmente, é possível afirmar que as conversações em rede formam uma ampla e diversificada arena de discussões, na qual os fãs trocam miríades de informes que potencializam sua própria apreciação dos seriados. Quanto mais complexa for a produção, mais se instiga a discussão em rede, e mais a cognição compartilhada se faz recompensada - nos atendo aos termos de Jenkins. Ou seja, há a geração duma contemplação profunda e com isso, se reforça ainda mais o elo dos fãs com suas obras queridas.

\section{BIBLIOGRAFIA}

Anchieta, W. (2017). Colorindo as sombras: indagações sobre o papel da cor no cinema narrativo. Dissertação de mestrado, UFF. Disponível em <http://www.ppgcom.uff.br/uploads/tese_185_9d2abf38d56 6b07e96f4851a652679d8.pdf >. Acesso em 16.02.17.

Batchelor, D. (2014). The Luminous And The Grey. Londres: Reaktion.

Bordwell, D. (1985). Narration In The Fiction Film. Wisconsin: The University of Wisconsin Press.

Blaszczyk, R. L. (2012). The Color Revolution. Cambridge: MIT Press.

Branigan, E. (2006). Projecting A Camera: Language-Games In Film Theory. Nova Iorque: Routledge.

Thrones (2017). Matéria disponível em $<$ https://networkdatascience.ceu.edu/article/2017-07-08/network-sciencepredicts-who-dies-next-game-thrones $>$. Acesso em 25.08.17. 
Caldwell, J. T. (1995). Televisuality: Style, Crisis, And Authority In American Television. New Jersey, Rutgers.

Chatman, S. (1978). Story and Discourse: narrative structure in Fiction and Film. Ithaca: Cornell University Press.

Colonna, V. (2010). L'art Des Séries Télé: Ou Comment Surpasser Les Américains. Paris: Payot \& Rivages.

Culler, J. (1999). Teoria Literária: Uma Introdução. São Paulo: Beca Produções Culturais.

Eco, U. (1993). Lector In Fabula: La Cooperacion Interpretativa Em El Texto Narrativo. Barcelona: Lumen, 1993.

Elm, M. (2009). How Do Various Notions Of Privacy Influence Decisions N Qualitative Internet Research? In: Marhkam, A.; Baym, N. Internet Inquiry. Conversations About Method. Los Angeles: Sage, P. 69-87.

Elsaesser, T.; Hagener, M. (2015). Film Theory: An Introduction Through The Senses. Nova Iorque: Routledge.

Fabro, N.; \& Kist, C. (2017). Era De Ouro Da TV: Séries De Primeira Superam A Indústria Cinematográfica. Galileu, 15.09. Disponível em <https://revistagalileu.globo.com/Revista/noticia/2017/09/e ra-de-ouro-da-tv-series-de-primeira-superam-industriacinematografica.html>. Acesso em 30.01.18.

Fragoso, S.; Recuero, R.; Amaral, A. (2013). Métodos De Pesquisa Para Internet. Porto Alegre: Sulina.

Gaudreault, A. (2009). From Plato to Lumière: narration and monstration in literature and cinema. Toronto: University of Toronto Press.

Gomes, W. (2004). La poética del cine y la cuestión del método en el análisis fílmico. In: Revista Significação, n. 21. Disponível em <http://www.revistas.usp.br/significacao/article/view/6558 4>. Acesso em 10.07.16.

Henn, R. (2014). El ciberacontecimiento: producción y semiosis. Barcelona: Editorial UOC, 2014.

Jenkins, H. (2006). Fans, Bloggers and Gamers: Exploring. On Participatory Culture. Nova Iorque: New York University Press, 2006. . (2008). Cultura Da Convergência. São Paulo: Aleph.

Jenkins, H.; Ford, S. E Green, J. (2013). Spreadable Media: Creating Value And Meaning In A Networked Culture. Nova York: New York University Press.

Johnson, S. (2005). Everything Bad Is Good For You: How Today's Popular Culture Is Actually Making Us Smarter. Nova Iorque: Riverhead. 
Kelson, T. (2008). And Now No Word From Our Sponsor: How HBO Puts The Risk Back Into Television. In: Leverette, M. et al (ed.) It's Not TV: Watching HBO In The Post-Television Era. Nova Iorque: Routledge, P. 46-64.

Larue, J. (2013). Infographic: Colorizing Walter White's Decay. TDYLF, 11.08. Disponível em <https://tdylf.com/2013/08/11/infographic-colorizingwalter-whites-decay/>. Acesso em 25.08.17.

Leslie, I. (2017). Watch It While It Lasts: Our Golden Age Of Television. Financial Times, 13.04. Disponível em <https://www.ft.com/content/68309b3a-1f02-11e7-a454ab04428977f9>. Acesso em 30.01.18.

Lesnovski, A. F. M. (2014). Uma Experiência Paradigmática: jogos e tensões no encontro entre a narrativa e a interatividade em forma audiovisual e eletrônica. Tese de Doutorado, PUC-RS. Disponível em <http://repositorio.pucrs.br/dspace/handle/10923/6843>. Acesso em 15.01.18.

Leverette, M.; L. Ott, B.; Buclkey, C. L. (org.). (2008). It's Not Tv: Watching Hbo In The Post-Television Era. Nova Iorque: Routledge.

Lévy, P. (1992). As Tecnologias Da Inteligência: O Futuro Do Pensamento Na Era Da Informática. São Paulo: Editora 34. . (2000). A Inteligência Coletiva: Por Uma Antropologia Do Ciberespaço. São Paulo: Edições Loyola.

Martel, F. (2013). Mainstream: A Guerra Global Das Mídias E Das Culturas. Rio De Janeiro: Civilização Brasileira. Versão eletrônica.

Mittell, J. (2015). Complex TV: The Poetics of Contemporary Television Storytelling. Nova Iorque: New York University Press. Versão eletrônica.

Moura, E. (2001). 50 Anos Luz, Câmera E Ação. São Paulo: Senac.

Neri, J. (2015). Mais Complexo Ou Menos Cômico? A Complexidade Narrativa Aplicada À Criação De Personagens Nas Novas Sitcoms. In: Culturas Midiáticas, n. 15. Disponível em <www.periodicos.ufpb.br/index.php/cm/article/viewFile/27 197/14500>. Acesso em 20.11.16.

Pedrosa, I. (2009). Da Cor à Cor Inexistente. Rio De Janeiro: Senac, 2009.

Plantinga, C. (2009). Moving Viewers: American Film and The Spectator's Experience. Berkeley: University of California Press.

Rose, G. (2001) Visual Methodologies: an introduction to the interpretation of visual materials. Londres: Sage. 
Ross, S. (2008). Beyond The Box: Television and The Internet. Oxford: Blackwell Publishing.

Silva, M. (2014). Cultura das Séries: Forma, Contexto e Consumo de Ficção Seriada na Contemporaneidade. Galáxia (São Paulo. Online), v. 14, p. 241-252.

Taussig, M. (2009). What Color Is The Sacred?. Chicago: University of Chicago Press.

Thompson, K. (1977). The Concept of Cinematic Excess. In: CinéTracts, vol 1, no 2. Disponível em <https://library.brown.edu/cds/cinetracts/CT02.pdf>. Acesso em 20.11.16

Verevis, C. (2006). Film Remakes. Edimburgo: Edinburgh University Press.

\section{FILMOGRAFIA}

Breaking Bad. Prod. exec. Vince Gilligan. AMC, EUA, 2014.

'Full Measure', Breaking Bad. Realizado por Vince Gilligan. AMC, EUA, 01/09/2013. 47mins.

Game of Thrones. Prod. exec. David Benioff. HBO, EUA, 2017.

'Ozymandias', Breaking Bad. Realizado por Rian Johnson. AMC, EUA, 15/09/2013. 47mins.

'Rabid Dog', Breaking Bad. Realizado por Sam Catlin. AMC, EUA, 01/09/2013. 47mins.

The Godfather. Realizado por Francis Ford Coppola. Paramount, EUA, 1972. 177mins.

The Sixth Sense. Realizador por M. Night Shyamalan. Hollywood Pictures, EUA, 1999. 177mins.

The Sopranos. Prod. exec. David Chase. HBO, EUA, 2014.

Twin Peaks. Prod. exec. Mark Frost. ABC, EUA, 2017. 